\title{
DIABETIC FOOT RISK ASSESSMENT AND FOOT CARE AMONG PATIENTS ATTENDING TERTIARY CARE HOSPITAL IN CENTRAL INDIA
}

\author{
Chaurasia $A^{1}$, Shaunak Valame ${ }^{2}$
}

${ }^{1}$ Associate Professor, Department of Medicine, SSMC, Rewa.

${ }^{2}$ Senior Resident, Department of Medicine, SSMC, Rewa.

\section{ABSTRACT}

\section{BACKGROUND}

India currently leads the world with largest number of diabetic subjects, earning the ignominy of being the "Diabetes capital of the world." Diabetic foot ulcer is a rising health problem, being the most important cause of non-traumatic foot ischaemia. Ulceration, infection, gangrene and lower extremity amputation are complications often encountered in diabetics. Not all foot complications can be prevented, but it is possible to dramatically reduce their incidence through appropriate management and prevention programs.

The aim of this study is to evaluate risk of development of diabetic foot among diabetics and to identify high risk features through Epidemiological variables, biochemical parameters and clinical findings of Ankle-Brachial Index, Monofilament testing and Durometer analysis.

Settings and Design- Cross-sectional study with educational intervention on 350 Diabetics attending Outpatient Department of Medicine at a tertiary care hospital in Central India.

\section{MATERIALS AND METHODS}

Diabetic Foot Risk Assessment questionnaire will be filled out by patients. Clinical assessment of their feet using Monofilament, Ankle Brachial Index and Durometer analysis of footwear along with Epidemiological Profile and Biochemical Parameters shall be correlated with their risk profile.

Statistical Analysis- Data analysis was done by calculating the p-value using the Chi-Square test using Microsoft Excel version 2016 (MS Office 365 Home).

\section{RESULTS}

Of 350 subjects 227 (64.86\%) had moderate risk of developing diabetic foot, while 87 (24.86\%) had high risk. Advanced age, rural lifestyle, low literacy, high body mass index, poor blood glucose control, longer duration of diabetes and addictions were significantly associated with a higher risk of developing diabetic foot. Ankle-Brachial Index, Monofilament Test and Durometer evaluation proved to be simple, cost-effective outpatient methods to evaluate risk profile.

\section{CONCLUSION}

Foot care assessment and inculcation of good foot care practices should be done at the outset of diagnosis of diabetes. Simple outpatient tests are sensitive enough to detect risk of developing diabetic foot. This approach may help reduce the incidence of diabetic foot.

\section{KEYWORDS}

Diabetes Mellitus, Diabetic Foot.

HOW TO CITE THIS ARTICLE: Chaurasia A, Valame S. Diabetic foot risk assessment and foot care among patients attending tertiary care hospital in central India. J. Evolution Med. Dent. Sci. 2017;6(72):5153-5158, DOI: 10.14260/Jemds/2017/1119

BACKGROUND
The burden of diabetes mellitus is already epidemic among Indians of Asian subcontinent. As per the World Health Organisation (WHO), India leads the world with 31.7 million diabetic subjects, which is expected to increase to 79.4 million by the year $2030 .{ }^{1} \mathrm{~A}$ recent epidemiologic study found that non-healing ulcers were seen in $41.51 \%$ of diabetics. ${ }^{2}$ Sociocultural practices such as bare foot walking, use of improper foot wear and lack of knowledge regarding foot care attributes towards increase in the prevalence of foot complications in India. ${ }^{3}$

Financial or Other, Competing Interest: None.

Submission 22-07-2017, Peer Review 25-08-2017,

Acceptance 31-08-2017, Published 07-09-2017.

Corresponding Author:

Dr. Shaunak Valame,

B-379, Sarita Vihar, New Delhi-110076.

E-mail: shaunak_valame@hotmail.com

DOI: $10.14260 /$ jemds $/ 2017 / 1119$
A 2008 - 09 study from Chennai found that total costs for patients without complications were Indian Rupees (INR) 4,493 compared to INR 14,691.75 for patients with complications. ${ }^{4}$ Among the different types of complications investigated, foot complications incurred the highest costs; patients with foot complications spent four times more than patients with no complications. ${ }^{5}$ These complications frequently result in extensive morbidity, repeated hospitalisations and mortality.

To develop diabetic foot one or more of the following three components is essential: Neuropathy, Vasculopathy and Infection. The fourth extremely important risk factor is increased plantar pressure. ${ }^{6}$ Sympathetic autonomic neuropathy in the lower limb results not only in reduced sweating and therefore dry skin that is prone to crack and fissure, but also to increase blood flow in the absence of large vessel peripheral vascular disease. This latter abnormality is a consequence of an increase in arteriovenous shunting and results from a warm foot with distended dorsal foot veins, 
both useful physical signs of an "at risk" foot. In a recent study assessing pathways to ulceration, neuropathy was the single most important component cause. ${ }^{7}$ In Indians, the prevalence of neuropathy in type 2 diabetic subjects has been reported to be $26.1 \%{ }^{8}$ The patient's history and physical examination utilising the Semmes-Weinstein monofilament (10 g) is sufficient to identify those individuals at risk for ulceration. ${ }^{9}$

Peripheral vascular disease (PVD) in diabetics differ from that in non-diabetics in many aspects. In non-diabetics, the sites of occlusion are usually the infrarenal aorta, iliac and superficial femoral arteries with sparing of distal vessels. Whereas, in diabetics, occlusive lesions occur in crural arteries namely tibials and peroneals with sparing of the arteries of the foot. ${ }^{10}$ Prevalence of PVD among Indians is considerably low as compared to the Western patients. Mohan et al have reported the prevalence of PVD in South Indian diabetics to be $3.9 \% .{ }^{11}$ Sphygmomanometry method of measuring Ankle-Brachial Index (ABI) is a reliable and reproducible method with sensitivity and specificity of $90 \%$ for evaluating PVD as well as a reliable method of indicating generalised atherosclerosis. ${ }^{12}$

The Durometer is the international standard for hardness measurement of rubber, plastic and other non-metallic materials. It evaluates resilience, plasticity and compression resistance of footwear. The softness of the footwear insole is helpful in the prevention of plantar ulcers. ${ }^{13}$ The final value of the hardness depends on the depth of the indenter after it has been applied for 15 seconds on the material.14 A value between 8 and 15 Shore Units is desirable for diabetic footwear. Value of less than 8 is too soft and unlikely to give protection, whereas a value above 15 is too hard leading to callosities due to pressure. ${ }^{15}$ Durometer may be a reliable screening tool to determine the degree of risk ${ }^{16}$ and assist in the institution of timely treatment. ${ }^{17}$

\section{MATERIALS AND METHODS}

This is a cross-sectional study with educational intervention on 350 diabetic patients attending Outpatient Department of Medicine at Sanjay Gandhi Memorial Hospital, Rewa, Madhya Pradesh from January 2015 to September 2015. Patients with Diabetic Foot related deformities were excluded. A careful history was recorded, general physical examination done and routine blood investigations sent. Diabetic Foot Risk Assessment Form ${ }^{18}$ was filled by each patient. Foot Assessment was done based on its structure, joint mobility, skin integrity, vascularity and sensory perception using Semmes-Weinstein monofilament (10 g). Footwear was evaluated by durometry. The foot was categorised on its risk of developing diabetic foot- Low, Moderate (Mod) or High. Patient was educated based on individual foot care practice.

\section{Statistical Analysis}

Data analysis was done by calculating the p-value using the Chi-square test using Microsoft Excel version 2016 (MS Office 365 Home).

\section{RESULTS}

\begin{tabular}{|c|c|c|c|c|c|}
\hline CHARACTERISTIC & \multicolumn{4}{|c|}{ DIABETIC FOOT RISK CATEGORY } & P-value \\
\hline AGE (Years) & LOW & MOD & HIGH & TOTAL & \multirow{5}{*}{ p $<0.05$} \\
\hline$<40$ & $19(41.30 \%)$ & $22(47.83 \%)$ & $5(10.87 \%)$ & 46 & \\
\hline $40-60$ & $44(26.51 \%)$ & $109(65.66 \%)$ & $13(7.83 \%)$ & 166 & \\
\hline \multirow[t]{2}{*}{$>60$} & $24(17.39 \%)$ & $96(69.57 \%)$ & $18(13.04 \%)$ & 138 & \\
\hline & 87 & 227 & 36 & 350 & \\
\hline LIFESTYLE & LOW & MOD & HIGH & TOTAL & \multirow{4}{*}{$\mathrm{p}<0.01$} \\
\hline RURAL & $25(16.34 \%)$ & $109(71.24 \%)$ & $19(12.42 \%)$ & 153 & \\
\hline \multirow[t]{2}{*}{ URBAN } & $62(31.47 \%)$ & $118(59.90 \%)$ & $17(8.63 \%)$ & 197 & \\
\hline & 87 & 227 & 36 & 350 & \\
\hline EDUCATION & LOW & MOD & HIGH & TOTAL & \multirow{5}{*}{$\mathrm{p}<0.01$} \\
\hline UNEDUCATED & $10(16.67 \%)$ & $41(68.33 \%)$ & $9(15 \%)$ & 60 & \\
\hline UPTO $12^{\mathrm{TH}}$ & $38(20.11 \%)$ & $130(68.78 \%)$ & $21(11.11 \%)$ & 189 & \\
\hline \multirow[t]{2}{*}{ GRADUATE AND ABOVE } & $39(38.61 \%)$ & $56(55.45 \%)$ & $6(5.94 \%)$ & 101 & \\
\hline & 87 & 227 & 36 & 350 & \\
\hline BODY MASS INDEX & LOW & MOD & HIGH & TOTAL & \multirow{6}{*}{ p $<0.05$} \\
\hline$<18.5$ & $9(37.50 \%)$ & $11(45.83 \%)$ & $4(16.67 \%)$ & 24 & \\
\hline $18.5-25$ & $54(28.27 \%)$ & $115(60.21 \%)$ & $22(11.52 \%)$ & 191 & \\
\hline $25-30$ & $24(18.46 \%)$ & $97(74.62 \%)$ & $9(6.92 \%)$ & 130 & \\
\hline \multirow[t]{2}{*}{$>30$} & 0 & $4(80 \%)$ & $1(20 \%)$ & 5 & \\
\hline & 87 & 227 & 36 & 350 & \\
\hline & Table 1. & iologic Profil & & & \\
\hline
\end{tabular}

As depicted in Table 1, Age and Body Mass Index (BMI) were significant $(\mathrm{p}<0.05)$ factors contributing towards the risk of development of diabetic foot. Eighteen subjects above the age of 60 years had a high risk compared to only 5 subjects who were under 40 years of age. Twenty percent of Class I Obese subjects had high risk compared to $11.52 \%$ of subjects with normal BMI. High risk comparison in Rural versus Urban sub-group (12.42\% vs $8.63 \%$ ) and Uneducated versus Graduate sub-group (15\% vs $5.94 \%)$ was also found to be highly significant $(\mathrm{p}<0.01)$. 


\begin{tabular}{|c|c|c|c|c|c|}
\hline \multirow{2}{*}{ TOBACCO USE } & \multicolumn{4}{|c|}{ RISK CATEGORY } & P-value \\
\hline & LOW & MOD & HIGH & TOTAL & \multirow{4}{*}{$\mathbf{p}<0.05$} \\
\hline YES & $41(25 \%)$ & $99(60.37 \%)$ & $24(14.63 \%)$ & 164 & \\
\hline \multirow[t]{2}{*}{ NO } & $46(24.73 \%)$ & $128(68.82 \%)$ & $12(6.45 \%)$ & 186 & \\
\hline & 87 & 227 & 36 & 350 & \\
\hline ALCOHOL & LOW & MOD & HIGH & TOTAL & \multirow{4}{*}{ p $<0.05$} \\
\hline YES & $29(34.94 \%)$ & $43(51.81 \%)$ & $11(13.25 \%)$ & 83 & \\
\hline \multirow[t]{2}{*}{ NO } & $58(21.72 \%)$ & $184(68.92 \%)$ & $25(9.36 \%)$ & 267 & \\
\hline & 87 & 227 & 36 & 350 & \\
\hline ALCOHOL+TOBACCO & LOW & MOD & HIGH & TOTAL & \multirow{4}{*}{$\mathrm{p}<0.01$} \\
\hline YES & $9(30 \%)$ & $12(40 \%)$ & $9(30 \%)$ & 30 & \\
\hline NO & $78(24.38 \%)$ & $215(67.19 \%)$ & $27(8.43 \%)$ & 320 & \\
\hline & 87 & 227 & 36 & 350 & \\
\hline
\end{tabular}

Among tobacco users $14.63 \%$ were at high risk of developing diabetic foot, while the same risk was seen in $13.25 \%$ alcohol users. This association was found to be significant $(p<0.05)$. However, $30 \%$ of subjects consuming alcohol and tobacco were at high risk which was found to be highly significant $(\mathrm{p}<0.01)$.

\begin{tabular}{|c|c|c|c|c|c|}
\hline MORBIDITY & \multicolumn{4}{|c|}{ RISK CATEGORY } & P-value \\
\hline DURATION (In Years) & LOW & MOD & HIGH & TOTAL & \multirow{6}{*}{$\mathrm{p}<0.01$} \\
\hline NEWLY DETECTED & $16(47.06 \%)$ & $17(50 \%)$ & $1(2.94 \%)$ & 34 & \\
\hline$<10$ & $33(30.56 \%)$ & $64(59.26 \%)$ & $11(10.18 \%)$ & 108 & \\
\hline $10-20$ & $27(16.98 \%)$ & $117(73.59 \%)$ & $15(9.43 \%)$ & 159 & \\
\hline \multirow[t]{2}{*}{$\geq 20$} & $11(22.45 \%)$ & $29(59.18 \%)$ & $9(18.37 \%)$ & 49 & \\
\hline & 87 & 227 & 36 & 350 & \\
\hline Glycated Haemoglobin $\left(\mathrm{HbA}_{1} \mathrm{c}\right)$ & LOW & MOD & HIGH & TOTAL & \multirow{5}{*}{ p $<0.05$} \\
\hline$\leq 7 \%$ & $20(32.26 \%)$ & $39(62.90 \%)$ & $3(4.84 \%)$ & 62 & \\
\hline $7.1-9.9 \%$ & $44(23.66 \%)$ & $128(68.82 \%)$ & $14(7.52 \%)$ & 186 & \\
\hline \multirow[t]{2}{*}{$\geq 10 \%$} & $23(22.55 \%)$ & $60(58.82 \%)$ & $19(18.63 \%)$ & 102 & \\
\hline & 87 & 227 & 36 & 350 & \\
\hline NEUROPATHY & LOW & MOD & HIGH & TOTAL & $\mathrm{p}<0.05$ \\
\hline YES & $49(21.21 \%)$ & $154(66.67 \%)$ & $28(12.12 \%)$ & 231 & \\
\hline \multirow[t]{2}{*}{ NO } & $38(31.93 \%)$ & $73(61.35 \%)$ & $8(6.72 \%)$ & 119 & \\
\hline & 87 & 227 & 36 & 350 & \\
\hline \multicolumn{6}{|c|}{ Table 3. Diabetes Morbidity } \\
\hline
\end{tabular}

Table 3 shows that $18.37 \%$ of subjects who had diabetes since $\geq 20$ years had a high risk of developing diabetic foot. Yet, the statistic that needs focusing is the fact that $50 \%$ of newly detected diabetics were already in the moderate risk group. Thus, duration since diagnosis was found to be highly significant $(\mathrm{p}<0.01)$. Subjects with well-controlled blood glucose level as measured by Glycated Haemoglobin had a significantly lower risk of developing foot-related complications compared to those with uncontrolled levels. Similarly, subjects showing signs and symptoms of neuropathy had a significantly higher risk (12.12\%) compared to those without neuropathy $(6.72 \%)$.

\begin{tabular}{|c|c|c|c|c|c|}
\hline Ankle-Brachial Index ${ }^{19}$ & LOW & MOD & HIGH & TOTAL & P-value \\
\hline$>1.3$ & $3(42.86 \%)$ & $1(14.28 \%)$ & $3(42.86 \%)$ & 7 & \multirow{4}{*}{$\mathbf{p}<0.01$} \\
\hline $0.91-1.3$ & $76(25 \%)$ & $203(66.78 \%)$ & $25(8.22 \%)$ & 304 & \\
\hline \multirow[t]{2}{*}{$\leq 0.9$} & $8(20.51 \%)$ & $23(58.98 \%)$ & $8(20.51 \%)$ & 39 & \\
\hline & 87 & 227 & 36 & 350 & \\
\hline FOOT SENSATION & LOW & MOD & HIGH & TOTAL & \multirow{5}{*}{$\mathbf{p}<0.01$} \\
\hline UNILATERAL REDUCED & $12(27.27 \%)$ & $23(52.27 \%)$ & $9(20.46 \%)$ & 44 & \\
\hline BILATERAL REDUCED & $8(17.02 \%)$ & $28(59.58 \%)$ & $11(23.40 \%)$ & 47 & \\
\hline \multirow[t]{2}{*}{ NORMAL } & $67(25.87 \%)$ & $176(67.95 \%)$ & $16(6.18 \%)$ & 259 & \\
\hline & 87 & 227 & 36 & 350 & \\
\hline $\begin{array}{l}\text { DUROMETER }{ }^{15} \\
\text { (Shore Units) }\end{array}$ & LOW & MOD & HIGH & TOTAL & \multirow{5}{*}{$\mathrm{p}<0.01$} \\
\hline $8-15$ & 0 & 0 & 0 & 0 & \\
\hline $16-35$ & $16(12.90 \%)$ & $96(77.42 \%)$ & $12(9.68 \%)$ & 124 & \\
\hline \multirow[t]{2}{*}{$>35$} & $71(31.42 \%)$ & $131(57.96 \%)$ & $24(10.62 \%)$ & 226 & \\
\hline & 87 & 227 & 36 & 350 & \\
\hline & f. Clinical & ers and Diak & ot Risk & & \\
\hline
\end{tabular}


The current study used 3 simple methods to clinically assess diabetic's foot. Ankle Brachial Index, Foot Sensation and Durometer analysis of footwear were all found to have highly significant contributions in increasing the likelihood of foot-related complications among diabetics. Only $8.22 \%$ of those with a normal ABI had high risk compared to $20.51 \%$ of those having PVD. Subjects with Unilateral (20.46\%) as well as Bilateral (23.40\%) reduced foot sensation had a significantly higher association with risk of developing footrelated complications as compared to those with normal foot sensation. Durometer analysis of footwear showed that no subject wore footwear that could adequately prevent foot trauma. Thus, it was a highly significant finding.

\section{DISCUSSION}

Age was a highly significant factor in influencing the risk of development of diabetic foot. Prevalence of high risk was highest above 60 years (13.04\%). This age category also accounted for 18 out of the 36 (50\%) patients who were found to be high risk. Similarly, Mayfield et al ${ }^{20}$ found most diabetic foot patients in the $56-65$ years' age group (34\%). As the diabetes epidemic spans all age groups, it is pertinent to start education regarding foot care among younger diabetics as well. Such education has the capability to retard, if not prevent, the development of diabetic foot.

Diabetics in rural areas are more prone to foot ulcers than those who live in urban areas. ${ }^{21}$ Similarly, the current study found $12.42 \%$ of the rural population had a 'high risk' of developing diabetic foot, contrasting significantly with just $8.63 \%$ of the urban group. Barefoot habit is more prevalent in the rural society, as is the lack of good footwear. These practices must be substituted with good foot care habits to reduce the complication of diabetic foot.

The current study evaluated the influence of formal education on risk of development of diabetic foot. We found a gradual, yet highly significant decline as the education level increased. Among the uneducated, 15\% had 'high risk' feet compared to $11.11 \%$ and $5.94 \%$ among those educated up to higher secondary and graduate levels, respectively. The current study also found that $74.62 \%$ of overweight diabetics had a moderate risk of developing diabetic foot, which was significantly higher than the $60.21 \%$ seen among normal weight diabetics. A socio-demographic study conducted in Kuala Lumpur also showed a higher incidence of diabetic foot among individuals with higher Body Mass Index (BMI) and higher prevalence among the primary schooled (38.4\%) compared to tertiary educated $(10.4 \%) .^{22}$ However, according to the current study, 22 out of the 36 'high risk' patients had normal BMI. Thus, although weight control should be preached by every physician, foot examination and education regarding healthy foot care habits must be carried out for normal BMI subjects as well as for the overweight.

Hence, it is pertinent that foot care must be individualised in accordance with age, living, education and BMI of the patient. A patient must be educated regarding foot care at an early age, especially from rural backgrounds having lower literacy levels. This would reduce the risk of diabetic foot among diabetics.

Among tobacco users (smokeless as well as smoked form), $14.63 \%$ had a high-risk foot which was significantly higher than the $6.45 \%$ among tobacco non-users. Similarly, Shahi et $\mathrm{al}^{23}$ found $5.15 \%$ of diabetic foot patients habituated to smoking and tobacco use. While the current study found $13.25 \%$ of alcohol users to have 'high risk' and $9.36 \%$ among teetotallers, the Shahi et al study ${ }^{23}$ found $12.37 \%$ patients with diabetic foot using alcohol. This comparison between the two studies shows the impact of such addictions have on development of diabetic foot. The current study also found that the risk was highly significant among those taking tobacco and alcohol (30\%) concurrently. Thus, besides healthy foot care practices, patients must also be counselled on their addictions.

Duration of diabetes is directly proportional to the risk of diabetic foot. Of those suffering from diabetes for $>20$ years, $18.37 \%$ had 'high risk' compared to $10.18 \%$ among those with diabetes since $<10$ years. Shahi et $\mathrm{al}^{23}$ found that patients with diabetic foot had a mean duration of diabetes of $11.5 \pm 5.74$ years. However, the most important finding of this study is that $50 \%$ of newly detected diabetics presented with 'moderate risk' of developing diabetic foot. These are the potential preventable targets, which consolidates the school of thought of educating patients right from the outset.

Strict blood glucose control was significantly associated with a lesser risk of diabetic foot. Only 3 (4.84\%) patients who had an $\mathrm{HbA}_{1} \mathrm{c} \leq 7 \%$ had a 'high risk,' while 19 of the 36 (52.78\%) 'high risk' patients had poor glycaemic control with an $\mathrm{HbA}_{1} \mathrm{c} \geq 10 \%$. It has been previously found by Peters et $\mathrm{al}^{24}$ that those patients with a history of foot ulcer had higher levels of blood glucose compared to those without ulceration.

Neuropathy was present in 231 of the 350 patients (66\%) in the current study. Li et al ${ }^{25}$ found $33.1 \%$ of diabetics in China to suffer from Peripheral Neuropathy. The current study found that risk of developing diabetic foot was significantly higher among those with neuropathy (12.12\%) as compared to those without (6.72\%). Moreover, the current study found that $61.35 \%$ of patients without neuropathic signs and symptoms had 'moderate risk' of developing diabetic foot. This finding underlines the importance of prevention being better than cure. Thus, awareness of foot care must be instituted as early after diagnosis as possible. This would reduce the progression of diabetic foot in a newly detected diabetic. At the same time, lack of neuropathic symptoms must not make doctors procrastinate in educating the patient.

In the current study, out of the 39 patients who had moderate or severe PVD (ABI $\leq 0.9$ ), 20.51\% had a 'high risk' of developing diabetic foot. Wang et $\mathrm{al}^{26}$ also found that $\mathrm{ABI}$ was significantly lower in those who had a lower limb amputation than those diabetics with cured diabetic foot ulcers.

Patients who had either unilateral or bilateral reduction in foot sensation had a significantly high risk of developing diabetic foot compared to their counterparts with normal foot sensation. Higher risk was seen in those patients who had bilaterally reduced foot sensations $(23.40 \%)$. The risk dropped to $20.46 \%$ among those with unilateral involvement and only $6.18 \%$ of those who had normal sensations. Peters et al24 similarly found abnormal Semmes-Weinstein monofilament test in $96.9 \%$ of patients with a history of foot ulcer.

The durometer is a new tool in the world of diabetes. It is of potential value in the assessment and monitoring of preulcerative disease, and could help to identify high-risk patients. ${ }^{17}$ Alarmingly, not a single subject examined in the 
current study had an adequate durometer footwear reading for a diabetic; $10.62 \%$ of those with a reading $>35$ Shore units had 'high risk' compared to $9.68 \%$ patients having a reading between 16 - 35. The authors of this study feel its regular usage in outpatient practice would assist in the institution of timely intervention by determining whether a certain footwear is appropriate for diabetics. Furthermore, the wear and tear of footwear would lead to inadequacy in protection. Regular monitoring of the in-sole hardness by durometer would help identifying this inadequacy at an early stage. Thus, it has the potential not only to predict the risk of progression of diabetic foot, but the patient can also be advised when to discard old footwear or change the in-soles.

\section{CONCLUSION}

Diabetes is said to be an 'iceberg disease,' and just as we do not pay attention to an iceberg's lower parts in the same manner we tend to forget the lower parts of a diabetic patient - the Feet. Hence, a lack of appropriate foot care awareness and footwear is a matter of genuine concern. A bright aspect, however, is the fact that we health care providers have an ample 'lead time' to prevent the onset of diabetic foot.

The current study has established the significance of demographic factors like Age, Rural-Urban lifestyle, Education and BMI towards evaluating a patient's foot. Factors such as addictions to tobacco and/or alcohol, duration since diagnosis of diabetes, blood glucose control and neuropathy are also of value in predicting potential foot complications.

To evaluate such risk we need simple, quick and effective methods to prognosticate our patients effectively. This study has found that Ankle-Brachial Index measurement, Foot sensation assessment and Durometer evaluation of patient's footwear to be three techniques through which this goal may be attained.

Moreover, education is a highly versatile tool which can be used to prevent, promote and maintain awareness regarding the complication of diabetic foot. Such education should be for all diabetic patients, not just those at 'high risk'; else this 'diabetic iceberg' phenomenon will 'sink' our titanic human population.

\section{REFERENCES}

[1] Wild S, Roglic G, Green A, et al. Global prevalence of diabetes: estimates for the year 2000 and projections for 2030. Diabetes Care 2004;27(5):1047-53.

[2] Jyothylekshmy V, Menon AS, Abraham S. Epidemiology of diabetic foot complications in a podiatry clinic of a tertiary hospital in South India. Indian J Health Sci Biomed Res 2015;8(1):48-51.

[3] Chandalia HB, Singh D, Kapoor V, et al. Foot wear \& foot care knowledge as risk factor for foot problems in Indian diabetics. Int J Diab Dev Ctries 2008;28(4):10913.

[4] Kumpatla S, Kothandan H, Tharkar S, et al. The costs of treating long-term diabetic complications in a developing country: a study from India. JAPI 2013;61(2):102-9.

[5] Yesudian CA, Grepstad M, Visintin E, et al. The economic burden of diabetes in India: a review of the literature. Globalization and Health 2014;10:80.
[6] Boulton AJ. The pathway to foot ulceration in diabetes. Med Clin North Am 2013;97(5):775-90.

[7] Reiber GE, Vileikyte L, Boyko EJ, et al. Causal pathways for incident lower-extremity ulcers in patients with diabetes from two settings. Diabetes Care 1999;22(1):157-62.

[8] Pradeepa R, Rema M, Vignesh J, et al. Prevalence and risk factors for diabetic neuropathy in an urban south Indian population: the Chennai Urban Rural Epidemiology Study (CURES-55). Diabetic Medicine 2008;25(4):407-12.

[9] Kumar S, Fernando DJ, Veves A, et al. SemmesWeinstein monofilaments: a simple, effective and inexpensive screening device for identifying diabetic patients at risk of foot ulceration. Diabetes Res Clin Pract 1991;13(1-2):63-7.

[10] Conrad MC. Large and small occlusion in diabetics and non-diabetics with severe vascular disease. Circulation 1967;36(1):89-91.

[11] Mohan V, Premalatha G, Sastry NG. Peripheral vascular disease in non-insulin dependent diabetes mellitus in South India. Diabetes Research and Clinical Practice 1995;27(3):235-40.

[12] Orchard TJ, Strandness DE. Assessment of peripheral vascular disease in diabetes. Report and recommendations of an international workshop sponsored by the American Diabetes Association and the American Heart Association September 18-20, 1992 New Orleans, Louisiana. Circulation 1993;88(2):819-28.

[13] Patil KM, Charanya G, Prabhu KG. Optical pedobarography for assessing neuropathic feet in diabetic patients--a review. Int J Low Extrem Wounds 2002;1(2):93-103.

[14] Gent AN. On the relation between indentation hardness and Young's modulus. Rubber Chemistry and Technology 1958;31(4):896-906.

[15] Ann JJ, Rachel CB, Rajan P, et al. In: Thomas N, Jeyaraman K, Asha HS, et al. eds. A practical guide to diabetes mellitus. $6^{\text {th }}$ edn. New Delhi: Jaypee Brothers Pvt Ltd., 2012.

[16] Cuaderes E, Khan MM, Azzarello J, et al. Reliability and limitations of the durometer and PressureStat to measure plantar foot characteristics in Native Americans with diabetes. Journal of Nursing Measurement 2009;17(1):3-18.

[17] Choh CT, Wall ML, Brown MD, et al. Use of durometry in assessment of venous disease. Phlebology 2010;25(2):94-9.

[18] Diabetes Foot Care Program of Nova Scotia. Foot Risk Assessment Form Guide. September 2009. http://diabetescare.nshealth.ca/sites/default/files/fil es/FootRiskAssessmentFormGuide.pdf

[19] Raman PG, Thakur BS, Mathew V. Ankle brachial index as a predictor of generalized atherosclerosis. JAPI 2001;49:1074-7.

[20] Mayfield JA, Reiber GE, Nelson RG, et al. A foot risk classification system to predict diabetic amputation in Pima Indians. Diabetes Care 1996;19(7):704-9. 
[21] Viswanathan V, Madhavan S, Rajasekar S, et al. Urbanrural differences in the prevalence of foot complications in South-Indian diabetic patients. Diabetes Care 2006;29(3):701-3.

[22] Misliza A, Ayu MS. Sociodemographic and Lifestyle Factors as the risk of diabetic foot ulcer in the University of Malaya Medical Centre. JUMMEC 2009;12(1):15-21.

[23] Shahi SK, Kumar A, Kumar S, et al. Prevalence of diabetic foot ulcer and associated risk factors in diabetic patients from North India. J Diabet Foot Compli 2012;4(3):83-91.
[24] Peters EJ, Lavery LA, International Working Group on the Diabetic Foot. Effectiveness of the diabetic foot risk classification system of the International Working Group on the Diabetic Foot. Diabetes Care 2001;24(8):1442-7.

[25] Li L, Chen J, Wang J, et al. Prevalence and risk factors of diabetic peripheral neuropathy in Type 2 diabetes mellitus patients with overweight/obese in Guangdong province, China. Primary Care Diabetes 2015;9(3):191-5.

[26] Wang A, Sun X, Wang W, et al. A study of prognostic factors in Chinese patients with diabetic foot ulcers. Diabetic Foot \& Ankle 2014;5:10.3402/dfa.v5.22936. 